\title{
Evaluation of a counselling protocol for predictive genetic testing for hereditary non-polyposis colorectal cancer
}

Katja Aktan-Collan, Jukka-Pekka Mecklin, Albert de la Chapelle, Päivi Peltomäki, Antti Uutela, Helena Kääriäinen

\begin{abstract}
Objectives-To evaluate the feasibility of a reduced counselling programme for predictive genetic testing for hereditary nonpolyposis colorectal cancer (HNPCC) in terms of counsellees' opinions on the extent and significance of genetic counselling and need for psychological support at different phases of the testing procedure. Design-Prospective follow up study with pre-test questionnaire assessment of background sociodemographic variables. The protocol comprised a pre-test counselling session, a period for reflection, and a test disclosure session. The outcome variables were studied by post-test questionnaires at one month and one year follow up.
\end{abstract}

Department of

Medical Genetics,

Haartman Institute,

University of Helsinki,

Helsinki, Finland

K Aktan-Collan

A de la Chapelle

P Peltomäki

Department of Surgery, Jyväskylä Central Hospital,

Jyväskylä, Finland J-P Mecklin

Human Cancer Genetics Program, Comprehensive

Cancer Center, Ohio

State University, Ohio,

USA

A de la Chapelle

Department of Epidemiology and Health Promotion,

National Public Health Institute, Helsinki,

Finland

A Uutela

Department of

Medical Genetics,

Family Federation of

Finland, PO Box 849,

FIN-00101 Helsinki,

Finland

K Aktan-Collan

H Kääriäinen

Correspondence to: Dr Kääriäinen

Revised version received 30 August 1999

Accepted for publication 15

September 1999
Subjects-Two hundred and seventy one high risk members of 36 families with HNPCC who attended both counselling sessions and completed the questionnaires.

Results-The pre-test counselling was considered fairly or very useful by $89 \%$ of respondents and one post-test session was considered sufficient by over $80 \%$ of respondents at follow up. Fifty three percent would have used extra psychological support had it been offered with the counselling. On enquiry one year after receiving the test result, only $2 \%$ stated that the need for support was at its greatest at that time, while the majority ( $46 \%)$ reported that the need for support had been greatest at the moment of test disclosure.

Conclusions-A protocol that includes one comprehensive pre-test counselling session and a test disclosure session, supplemented with the option of professional psychological support, seems to be sufficient for both the educational and supportive needs of counsellees. Only a minority expressed a need for post-test follow up sessions, which suggests that, in this disorder, resources can be directed to the beneficial surveillance programmes rather than to extensive psychological support.

( $\mathcal{H}$ Med Genet 2000;37:108-113)

Keywords: predictive genetic testing; genetic counselling; HNPCC; hereditary non-polyposis colorectal cancer

Presymptomatic genetic testing for late onset hereditary diseases first became possible in autosomal dominant, adult onset Huntington's disease (HD), a disease for which there is no prevention or cure. ${ }^{1}$ Experience of testing for HD has resulted in widely accepted guidelines for genetic counselling protocols which comprise a minimum of two pre-test educational sessions and several post-test sessions combined with psychological support. ${ }^{2-6}$ The extensiveness of the protocol has been suggested to be one of the reasons for the low uptake of the presymptomatic genetic test for $\mathrm{HD}$, but also for the low rate of serious adverse psychological reactions after testing positive. ${ }^{7}$

Along with the characterisation of genes predisposing to some common hereditary cancers, such as breast cancer and colon cancer, genetic testing has become relevant for healthy members of families with these disorders. ${ }^{8-10}$ So far, the counselling programmes in predictive genetic testing for hereditary cancer have followed more or less the recommendations created for HD. ${ }^{11-15}$ However, experience of predictive testing for cancer is still very limited. The importance of research before offering testing as part of normal health care routines has been emphasised repeatedly. ${ }^{16-21}$

In 1995, in a research setting, we offered counselling and predictive testing to 446 subjects at high risk for hereditary nonpolyposis colorectal cancer (HNPCC), an autosomal dominantly inherited disease. For subjects carrying the mutation, the risk of developing multiple cancers (mainly colon, endometrial, and stomach cancer) at a comparatively young age is at least $80 \%{ }^{22}$ Existing methods of clinical cancer surveillance, especially regular colonoscopies aimed at early detection and removal of tumours at a premalignant stage, have improved the prognosis of those at risk in terms of morbidity and mortality. ${ }^{22} 23$ As an extensive protocol will probably not be feasible in hereditary cancers, which are far more common than HD, ${ }^{124}$ we wanted to test a reduced protocol modified from that for $\mathrm{HD}$, omitting the second pre-test counselling session and offering more than one post-test session only on request. Our aim was to let those who had taken the predictive genetic test for HNPCC evaluate this protocol in terms of the need for psychological support experienced at different phases of the testing procedure and to hear their opinions about the extent and significance of genetic counselling.

\section{Methods}

TESTING PROCEDURE

During 1995-1997, we offered counselling about predictive genetic testing to adults at 


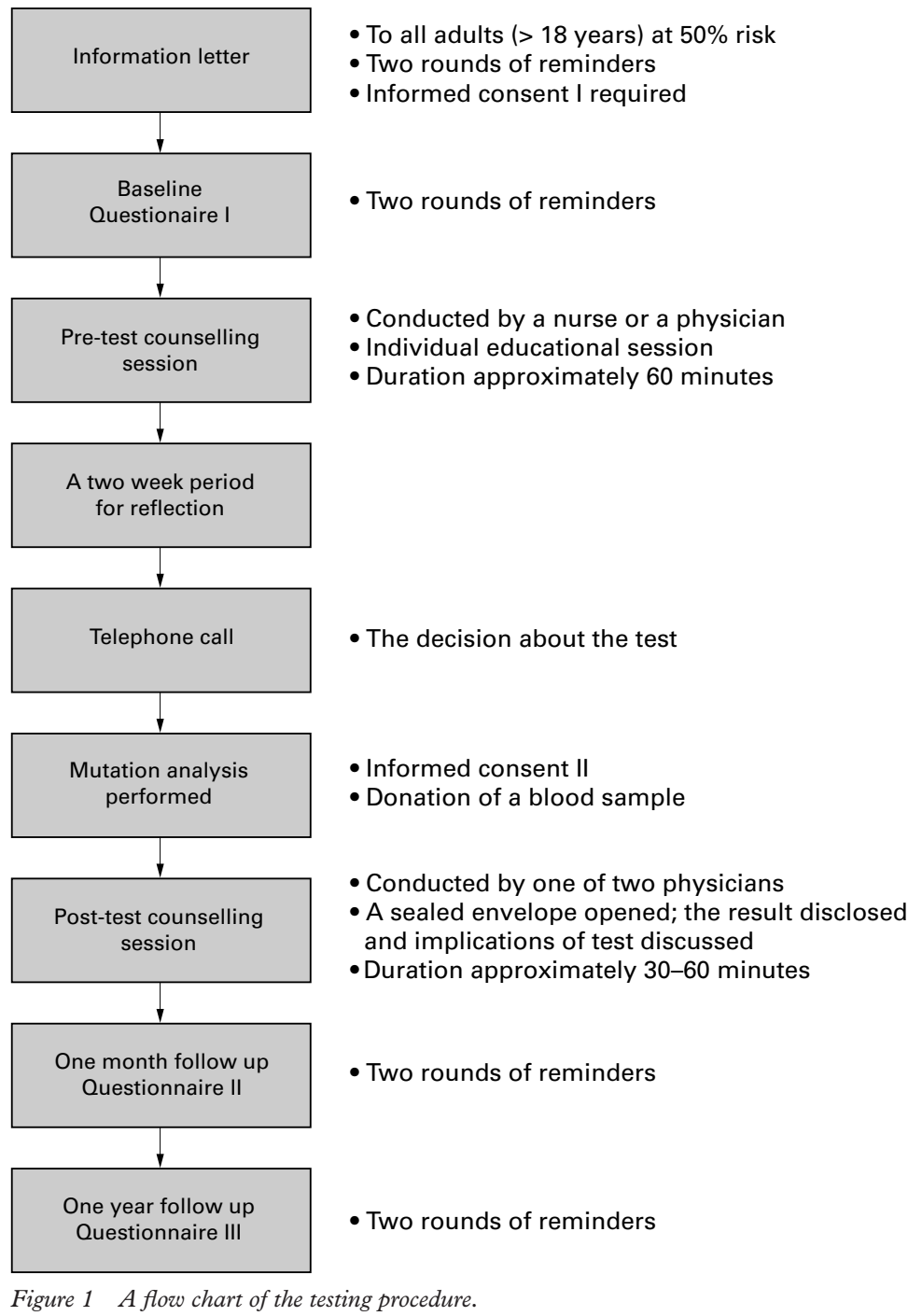

$50 \%$ risk in 36 HNPCC families with three different previously characterised mutations in the MLH1 gene..$^{25-27}$ Subjects were considered eligible if they were aged 18 or older, without a diagnosis of cancer, and without any cognitive disorder that precluded informed consent. The scheme of the counselling protocol is illustrated in fig 1 . The pretest counselling session included taking the family history and giving information about HNPCC, its mode of inheritance, the gene defect, the nature and risk of colon cancer, the risk of other cancers, and the methods available for early detection of tumours. The benefits and disadvantages of a predictive genetic test were discussed, including psychological reactions, and possible difficulties with employment or insurance coverage in the future.

After a two week period for reflection, counsellees were contacted by telephone and asked if they wanted the test. Those who chose to take the test signed a consent form and donated a blood sample. Those who declined the test were encouraged to take advantage of the offer of clinical surveillance comprising colonoscopy every three years and gynaecological examinations for females over 35 years every 18 months.
Those tested were invited, preferably with an accompanying person, to a post-test counselling session at which the test result and its implications were discussed. Clinical surveillance was organised for those carrying the mutation. Subjects who did not have the mutation were reminded of the general risk of cancer to prevent any false reassurance. The result and its interpretation were also given in written form.

Of the eligible subjects ( $\mathrm{n}=446), 90 \%$ $(n=401)$ consented to the study and $85 \%$ $(\mathrm{n}=381)$ returned the baseline questionnaire $\mathrm{I}$. The educational counselling session was attended by 347 subjects, of whom 333 (96\%, $75 \%$ of the total population) opted for a predictive genetic test. Thirty percent of those tested chose to have an accompanying person at the test disclosure session. Seven subjects refused to fill in any further questionnaires. Questionnaire II was sent to 326 subjects, of whom 299 (92\%) replied. Questionnaire III was sent to these 299 subjects, of whom 271 (91\%) completed this final round. Thus, the study sample consisted of those 271 subjects who attended both counselling sessions and completed the pre- and post-test questionnaires. Of the subjects, $63 \%$ attended the pre-test session conducted by a nurse and 37\% by a physician specialising in medical genetics (KA-C). Fifty seven percent had a post-test counselling session conducted by the same physician (KA-C) and the rest were counselled by a gastroenterological surgeon (J-PM). The counsellors were trained specifically for this project.

\section{SOCIODEMOGRAPHIC CHARACTERISTICS}

Those who completed the questionnaire study were aged 19 to 77 years. The mean age of these study participants was 43 years (SD 13 years) and that of the Finnish population with similar age limits 45 years. Other sociodemographic characteristics of the study participants and Finnish population are shown in table 1 . The subjects lost to follow up $(n=62)$, who did not complete questionnaires after the post-test counselling session, did not differ significantly from the study subjects in any of the variables described.

\section{QUESTIONNAIRES AND ANALYSES}

The study was based on questionnaires, which were filled in three times during the procedure (fig 1). Sociodemographic factors were assessed from baseline questionnaire I. All other information was obtained from follow up questionnaires II and III.

Opinions on the counselling sessions were assessed by the following items. (1) What is your general opinion about the counselling protocol $(1=$ counselling sessions were easily comprehensible and I have no improvements to suggest, 2 =counselling sessions were easily comprehensible but I would like to suggest the following minor changes concerning the counselling sessions ..., 3=I would like to suggest major changes concerning the counselling sessions, such as...)? (2) Did you consider the pretest counselling session useful ( $1=$ very useful, 
Table 1 Sociodemographic descriptions of the study participants $(n=271) 19$ to 77 years of age and of Finnish population of similar ages

\begin{tabular}{|c|c|c|}
\hline Variables & $\begin{array}{l}\text { Study group \% } \\
\text { (No) }\end{array}$ & $\begin{array}{l}\text { Finnish } \\
\text { population } * \%\end{array}$ \\
\hline \multicolumn{3}{|l|}{ Gender } \\
\hline Female & $57(155)$ & 52 \\
\hline \multicolumn{3}{|l|}{ Marital status } \\
\hline Living with spouse or partner & $72(196)$ & 61 \\
\hline Widowed, single, divorced & $28(75)$ & 39 \\
\hline \multicolumn{3}{|l|}{ Having children } \\
\hline Yes & 73 (199) & $\dagger$ \\
\hline \multicolumn{3}{|l|}{ Employment status } \\
\hline Employed & $75(202)$ & 58 \\
\hline Unemployed or retired & $25(67)$ & 42 \\
\hline \multicolumn{3}{|l|}{ Highest level of education } \\
\hline Primary education & $37(100)$ & 45 \\
\hline Vocational or upper secondary education & $52(142)$ & 43 \\
\hline University education & $11(29)$ & 12 \\
\hline \multicolumn{3}{|l|}{ Under clinical surveillance } \\
\hline Yes & $68(184)$ & \\
\hline \multicolumn{3}{|l|}{ Gene test result } \\
\hline Mutation negative & $69(187)$ & \\
\hline Mutation positive & $31(84)$ & \\
\hline
\end{tabular}

^Data from Statistics Finland (from 1995).

†Data not available.

Table 2 Perceived sufficiency of single post-test counselling session (No (\%))

\begin{tabular}{lll}
\hline Question & $\begin{array}{l}\text { One month follow up } \\
\text { No (\%) }\end{array}$ & $\begin{array}{l}\text { One year follow up } \\
\text { No (\%) }\end{array}$ \\
\hline $\begin{array}{l}\text { Did you consider one post-test counselling session sufficient? } \\
\text { Yes, it was sufficient }\end{array}$ & $237(89)$ & $228(85)^{\star}$ \\
$\begin{array}{l}\text { No, I would have liked an additional counselling } \\
\text { session }\end{array}$ & $10(3)$ & $13(5)$ \\
$\begin{array}{l}\text { Can't say } \\
\text { Total }\end{array}$ & $20(8)$ & $27(10)$ \\
\end{tabular}

${ }^{\star} \mathrm{McNemar}$ test: $\mathrm{p}$ value $=1.000$ (one month follow up $v$ one year follow up).

Table 3 Use of psychological support

\begin{tabular}{ll}
\hline & \multicolumn{1}{l}{ Answer chosen by } \\
\cline { 2 - 2 } Question & No (\%) \\
\hline $\begin{array}{l}\text { Would you have welcomed psychological support provided by the } \\
\text { counselling team? } \\
\text { (1) Definitely }\end{array}$ & $16(6)$ \\
(2) Most likely & $41(15)$ \\
(3) Perhaps & $85(32)$ \\
(4) Most unlikely & $111(41)$ \\
(5) Definitely not & $15(6)$ \\
\hline
\end{tabular}

2 =fairly useful, $3=$ slightly useful, $4=$ not at all useful, $5=$ can't say)? In data analysis, options 1 and 2 were combined to "useful", and 3, 4, and 5 to "not so useful". (3) Did you consider one post-test counselling session sufficient? (See options in table 2.)

The need for psychological support experienced during the testing procedure was assessed by three questions offering multiple choices. (1) If professional psychological support had been offered by our group in addition to the counselling, would you have made use of it? (See options in table 3.) For data analysis, we combined options 1,2 , and 3 , and also 4 and 5; the categories are referred to as "might have used the support" and "might not have used the support", respectively. (2) At which moment did you experience the greatest need for psychological support? (See options in fig 2.) (3) Did you seek psychological help or use mental health services because of the genetic test result $(1=$ yes, $2=$ no)?

The answers to these questions were cross tabulated by sociodemographic variables to assess statistical associations between the variables. All data analyses were done with program SPSS for Windows version 7.0.
Chi-square and McNemar tests were used to determine whether there were differences for categorical variables. The significance of the differences between continuous variables was measured with the $t$ test. For the analyses, the $\mathrm{p}$ values were two tailed and a $p$ value of less than 0.05 was considered to indicate statistical significance.

\section{Results}

None of the respondents suggested major changes in the counselling. At the one month follow up, $88 \%(n=237)$ of the respondents indicated that counselling was easily comprehended and suggested no changes to the pre- or post-test counselling. Ten percent $(n=26)$ of the counsellees proposed minor changes, most commonly asking for more written material concerning methods of clinical surveillance and prevention. Those who had a university education suggested changes to the counselling more often than others $\left(\chi^{2}=11.98, \mathrm{df}=2\right.$, $\mathrm{p}<0.01$ ).

At the one year follow up, the pre-test counselling sessions were considered very useful by $49 \%$ of the respondents, fairly useful by $40 \%$, and slightly useful by $10 \%$, while $1 \%$ had no definite opinion. Gender and education were significantly associated with the perceived usefulness of the counselling. Women $\left(\chi^{2}=5.71\right.$, $\mathrm{df}=1, \mathrm{p}<0.05)$ and those with a lower level of education $\left(\chi^{2}=9.23 \mathrm{df}=2, \mathrm{p}<0.05\right)$ more often considered the counselling useful than the others.

Table 2 shows the satisfaction with the counselling protocol that included a single post-test session. At post-test follow ups, $89 \%$ and $85 \%$, respectively, considered a single post-test session sufficient. Having children was positively associated with the opinion that an additional post-test session would have been desirable $\left(\chi^{2}=8.45, \mathrm{df}=1, \mathrm{p}<0.01\right)$.

Altogether $53 \%$ of the respondents indicated that they might have used professional psychological support along with the counselling if it had been provided by the counselling team (table 3). The support might have been used by women with children more often than by others $\left(\chi^{2}=8.26, d f=1, p<0.01\right)$. Fig 2 presents opinions about the need for psychological support experienced. Fourteen percent (37/271) of the respondents could not decide or mentioned several different phases at which the need for support was greatest. These 37 subjects were excluded from further data analysis aimed at finding associations between sociodemographic variables and the need for psychological support at a particular phase. The need for support at the decision making phase was experienced more often by men than by women $\left(20 \% v 7 \%, \chi^{2}=7.97, \mathrm{df}=1, \mathrm{p}<0.01\right)$, whereas women emphasised the support at the test result disclosure session phase $(52 \% v$ $\left.35 \%, \chi^{2}=5.68, \mathrm{df}=1, \mathrm{p}<0.05\right)$. Those who stated that they needed most support when the test result was being disclosed were slightly younger than those who did not (mean age 41 years $v 45$ years, $t$ test $=1.98, \mathrm{df}=207, \mathrm{p}<0.05)$. The mutation positive subjects more often reported that they had had greatest need for 


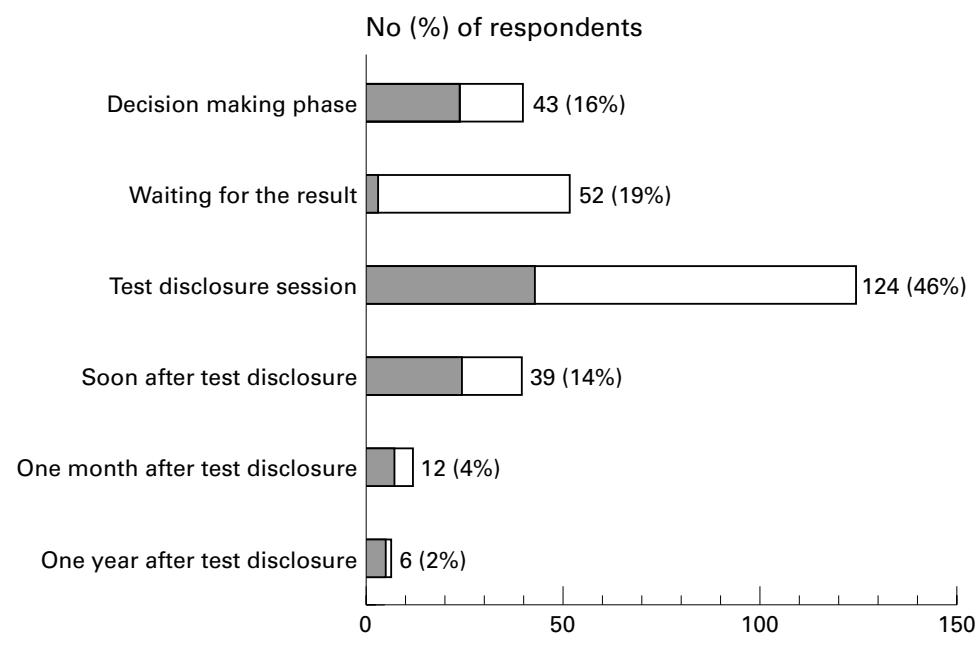

Mutation negative group

Mutation positive group

Figure 2 The phase of the testing procedure at which the need for psychological support was experienced as greatest when enquired about one year after the test disclosure.

support soon after hearing the result than the mutation negative subjects $(19 \%$ v $6 \%$, $\chi^{2}=7.39, \mathrm{df}=1, \mathrm{p}<0.01$ ), whereas the mutation negative subjects more often felt that they had greatest need for support while waiting for the test result $\left(26 \%\right.$ v $3 \%, \chi^{2}=15.73 \mathrm{df}=1$, $\mathrm{p}<0.0001)$. Two subjects $(1 \%)$ reported that they had sought professional psychological help from the mental health services. At follow up, neither of them stated that they would have desired additional post-test counselling.

\section{Discussion}

Predictive genetic testing will reach new dimensions when genes predisposing to common diseases become known, and this places increasing pressure on genetic services, because it inevitably will lead to more patients and relatives being tested. It is, therefore, essential to study the feasibility and acceptance of practical protocols of counselling used in common diseases. In the present study, we investigated the need for psychological support experienced at different phases of the testing process for HNPCC and experiences of genetic counselling in a research setting.

Of the 446 high risk members contacted in the 36 HNPCC families, the great majority $(75 \%)$ took the test; afterwards, most of them were satisfied with their decision and very few regretted it (K Aktan-Collan, in press). However, in the present study, $53 \%$ of the study subjects, especially the women with children, stated that they might have used professional psychological support if it had been actively offered to them. In general, women consult doctors about emotional distress more often than men. ${ }^{28}$ They also tend to express adverse emotional reactions related to predictive genetic testing more openly and to be more intimately involved with their offspring, ${ }^{29}{ }^{30}$ which may explain why they were more likely to want professional support. These results suggest that the option of professional psychological support should be offered as part of the testing procedure. On the other hand, only $1 \%$ had sought professional psychological help. The need for support was apparently relative and the great majority were probably coping sufficiently, and even well, without professional help. To resolve this issue thoroughly, long term studies on the psychological implications of such testing are needed.

On enquiry one year after receiving the test result, only $2 \%$ stated that the need for support was at that time at its greatest. This suggests that the most distressing part of the predictive testing procedure was in most cases now over and the subjects had adjusted to the situation. The need for support was perceived to have been greatest at the time of the decision making, when waiting for the results, and, especially, at the moment of receiving the test results. In fact, our protocol had been designed with these important phases of the procedure especially in mind. The pre-test counselling lasted for an hour and contained, in addition to information, discussion of the possible positive and negative consequences of the test. This thorough discussion was aimed at adapting the counsellees to cope with the test result and perhaps, therefore, the later phases of the programme were not experienced as so difficult.

Tibben et $a l^{\beta 1}$ reported that carriers of the HD mutation experienced the pre-test period as the most stressful time in the testing procedure. In our study, this period was considered especially important by men and mutation negative subjects. The latter can be explained by the retrospective nature of this question. Understandably, the mutation negative subjects felt more distressed before hearing the result than afterwards when they looked back at the issue after a year. By contrast, women and mutation positive and younger subjects experienced the greatest need for support immediately and soon after hearing the result. This should be kept in mind by allowing ample time for the test disclosure session and strongly encouraging the counsellees to bring an accompanying person to this event.

A majority of our participants considered the counselling sessions useful and did not suggest any improvements concerning them. A minority would have been glad of written educational information during the counselling. (On the basis of these opinions, we have prepared an HNPCC information booklet including basic knowledge about HNPCC, which was sent to the participants with questionnaire III.) The less educated the counsellees were, the more satisfied they were with the counselling. This may have been because they had been less active in searching for information on their own and more often lacked knowledge initially and therefore gained more from the counselling. Women found the pre-test counselling more useful than men. This may reflect the fact that women in general make more use of medical services and have a more positive attitude towards health care than men. ${ }^{32}$ Alternatively, it could indicate that men might have been less interested in the psychosocial issues raised in the session than women or they might have felt that they already had enough information to 
make the decision regarding the test before the counselling. It is also possible that the pre-test counselling was given in a way that was more acceptable to women than to men.

Only a handful of the counsellees would have been glad to discuss the post-test information with the physician again; the great majority considered one post-test session sufficient and the desire for additional counselling was not associated with the use of mental health services. These findings suggest that offering a single post-test session is adequate, provided that an option of a second session is included.

It should be noted that the subjects in this study were only familiar with the present protocol and could not compare it with the more comprehensive one used in HD. Previous studies have shown that extremely different forms of counselling protocols are accepted without dissatisfaction. ${ }^{33}{ }^{34}$ In two reports of testing for cystic fibrosis (CF) carriers, in which the different types of pre-test education, clinic (including a genetic counselling session) and home based (comprising an educational pamphlet) education, for at risk subjects were compared, there was a tendency to prefer education and testing in the home, ${ }^{33}$ but no significant differences were found between the groups regarding knowledge about CF, anxiety, emotional effects, or satisfaction with the testing. ${ }^{34}$ Those who merely read the pamphlet found the testing more convenient but were more confused by it than those who had attended a genetic counselling session. Furthermore, in predictive genetic testing for breast cancer, research on pre-test education has indicated that a counselling based approach increases awareness of negative aspects of the predictive testing, but does not decrease interest in the testing compared with a merely educational approach without counselling, ${ }^{35}$ which seems to support the statement that counselling in the course of predictive testing is essential to avoid decisions being taken too lightly. ${ }^{18}$

The time required for the present protocol was reasonable; the two counselling sessions (11/2-2 hours) and telephone calls (10-30 minutes) took at most $2 \frac{1 / 2}{2}$ hours per counsellee. The counselling sessions were conducted by three different counsellors (a nurse, a physician specialising in medical genetics, and a gastroenterological surgeon). However, the analyses showed no statistically significant differences between the counsellors regarding any of the outcome variables. Thus, professionals of different kinds can be trained to perform genetic counselling for HNPCC as long as the high standards of counselling, such as confidentiality and autonomy of the counsellee, are respected and maintained.

LIMITATIONS OF THE STUDY

Our study differed in some respects from a non-research setting. Firstly, all counselling and testing procedures were free of charge for the participants as well as for the communities. Secondly, the majority of our subjects had participated in the clinical surveillance and had already been living with the idea of being at high risk for years. Their opinions, however, did not differ significantly from those not under clinical surveillance. Thirdly, the answers of the study subjects may have been biased in a positive direction, as the same team who was involved with the questionnaire study also provided the counselling and organised the clinical surveillance. For this reason, the participants may have felt uncomfortable admitting dissatisfaction or suggesting changes to the protocol. Fourthly, those who had the most negative attitudes towards the counselling may be those who did not complete the questionnaire study. However, since there were no baseline differences between those who completed the questionnaires and those who did not, a significant bias is unlikely to exist. By contrast, it is possible that those completing the questionnaires represented a slightly more educated and employed proportion of the Finnish population (table 1), which may have affected the study compliance. On the other hand, general response rates to health surveys in Finland are high (50-90\%). ${ }^{36}$

\section{Conclusions}

The uptake of a predictive test was high in Finnish HNPCC families; $75 \%$ of those contacted and $96 \%$ of those attending counselling took the test. However, the present study suggests that making the decision was psychologically demanding and, apparently, the moment of the test result disclosure was even more stressful. With time, coping with the test result was found to be easier. This may be because of the existing beneficial surveillance and early treatment of cancer, which increases the sense of security among the mutation positive subjects and, for the same reason, decreases the feelings of survivor guilt among those receiving the good news.

Thus, our results support the view that, for the purpose of genetic counselling and predictive testing for HNPCC, the reduced form of the counselling protocol is suitable. A protocol that includes one comprehensive educational pre-test counselling session and a test disclosure session, supplemented with the option of professional psychological support, seems to be sufficient for both the educational and the supportive needs of counsellees at the psychologically critical phases. Only a minority expressed need for post-test follow up sessions, which suggests that, in this disorder, resources can be directed to the beneficial surveillance programmes rather than to extensive psychological support.

We wish to thank Mrs Marjo Molin for her contribution to the pre-test counselling and Mrs Tuula Lehtinen and Mrs Kirsi Pylvänäinen for their expert assistance. This study was supported by grants from the Academy of Finland, the Finnish supported by grants from the Academy of Finland, the Finnish Cancer Society, the European Commission (contract BMH4CT96-0772), and the US National Institutes of Health grants the Folkhälsan Institute of Genetics.

1 Harper PS. Huntington's disease. London: Saunders, 1991. 2 International Huntington Association and the World Federation of Neurology Research Group on Huntington's Chorea. Guidelines for the molecular genetics predictive test in Huntington's disease. 7 Med Genet 1994,3

3 Tibben A, Vegter-van der Vlis M, Skraastad MI, et al. DNA testing for HD in the Netherlands: a retrospective study on psychosocial effects. Am F Med Genet 1992;44:94-9. 
4 Quaid, KA. Presymptomatic testing for Huntington's disease. Recommendations for counselling f Genet Couns 1992;1:227-301.

5 Bennett RL, Bird TD, Teri L. Offering predictive testing for Huntington disease in a medical genetics clinic: practical applications. F Genet Couns 1993;2:123-7.

6 Benjamin CM, Wiggins S, Theilmann JL, et al. Proceed with care: direct predictive testing for Huntington disease. Am $\mathcal{F}$ Hum Genet 1994;55:606-12.

7 Kessler S. Predictive testing for Huntington disease: a psychologist's view. Am f Med Genet 1994;54:161-6.

8 Miki Y, Swensen J, Shattuck-Eidens D, et al. A strong candidate for the breast and ovarian cancer susceptibility gene BRCA1. Science 1994;266:66-71.

9 Wooster R, Bignell G, Lancaster J, et al. Identification of the breast cancer susceptibility gene BRCA2. Nature 1995;378: 789-92.

10 Kinzler KW, Vogelstein B. Lessons from hereditary colorectal cancer. Cell 1996;87:159-70.

11 Lerman C, Narod S, Schulman K, Hughes C, GomezCaminero A, Bonney G. BRCA1 testing in families with heredita 92.

12 Lynch HT, Drouhard T, Vasen HFA, et al. Genetic counselling in a Navajo hereditary nonpolyposis colorectal cancer kindred. Cancer 1996;77:30-5

13 Lerman C, Hughes C, Trock BJ, et al. Genetic testing in families with hereditary nonpolyposis colon cancer. $\mathcal{F} A M A$ 1999;17:1618-22.

14 DudokdeWit AC, Tibben A, Duidenvoorden HJ, et al. Psychological distress in applicants of predictive DNA testing for autosomal dominant inheritable late onset disorders. $\mathscr{F}$ Med Genet 1997;34:382-91.

15 Vernon SW, Gritz ER, Peterson SK, et al. Correlates of psychological distress in colorectal cancer patients undergoing genetic testing for hereditary colon cancer. Health Psychol 1997;16:73-86.

16 American Society of Human Genetics. Statement of the American Society of Human Genetics on genetic testing American Society of Human Genetics on genetic testing Genet 1994;55:ii-iv.

17 National Center for Human Genome Research. Statement on use of DNA testing for presymptomatic identification of cancer risk. $\mathcal{F A M A} 1994 ; 271: 785$.

18 Statement of the American Society of Clinical Oncology. Genetic testing for cancer susceptibility. F Clin Oncol 1996; 14:1730-6

19 Collins F. BRCA1 Lots of mutations, lots of dilemmas. $N$ Engl f Med 1996;334:186-8.

20 Harper PS. What do we mean by genetic testing? $7 \mathrm{Med}$ Genet 1997;34:749-52.

21 Ponder B. Genetic testing for cancer risk. Science 1997;278 1050-4.

22 Lynch HT, Smyrk T. Hereditary nonpolyposis colorectal cancer (Lynch syndrome): an updated review. Cancer 1996;78:1149-67.
23 Järvinen $\mathrm{H}$, Mecklin JP, Sistonen P. Screening reduces colorectal cancer rate in families with hereditary nonpolyposis colorectal cancer. Gastroenterology 1995;108:1405-11.

24 Aaltonen LA, Salovaara R, Kristo P, et al. Incidence of hereditary nonpolyposis colorectal cancer and the feasibility of molecular screening for the disease. $N \mathrm{Engl} \mathcal{F} \mathrm{Med}$ 1998;338:1481-7.

25 Nyström-Lahti M, Kristo P, Nicolaides NC, et al. Founding mutations and Alu-mediated recombination in hereditary colon cancer. Nat Med 1995;1:1203-6.

26 Nyström-Lahti M, Wu Y, Moisio AL, et al. DNA mismatch repair gene mutations in 55 kindreds with verified or putative hereditary nonpolyposis colorectal cancer. Hum $\mathrm{Mol}$ Genet 1996;5:763-9.

27 Holmberg M, Kristo P, Chadwick RB, et al. Mutation sharing and predominant involvement of the MLH1 gene in hereditary nonpolyposis colorectal cancer. Hum Mutat Mutation in Brief No 144 (online) 1997. Available from: URL: http://journals.wiley.com/1059-7794/html/mutation/ URL: http://jo

28 Doyal L. What makes women sick: gender and political economy of health. London: Macmillan Press, 1995

29 Dudok de Wit AC, Duivenvoorden HJ, Passchier J, et al. Course of distress experienced by persons at risk for an autosomal dominant inheritable disorder participating in a predictive testing program: an explorative study. Psychosom Med 1998;60:543-9.

30 Bloch M, Fahy M, Fox S, Hayden MR. Predictive testing for Huntington disease. II. Demographic characteristics, life-style patterns, attitudes, and psychosocial assessments of the first fifty-one test candidates. Am F Med Genet 1989; 32:217-24.

31 Tibben A, Frets PG, van de Kamp JJP, et al. On attitudes and appreciation 6 months after predictive DNA testing for Huntington disease in the Dutch program. Am $\mathcal{F}$ Med Genet 1993;48:103-11.

32 Taylor SE. Health psychology. New York: McGraw Hill, 1995.

33 Sorenson JR, Cheuvront B, DeVellis B, et al. Acceptance of home- and clinic-based cystic fibrosis carrier education and testing by first, second and third degree relatives of cystic fibrosis patients. Am f Med Genet 1997;70:121-9.

34 Cheuvront B, Sorenson JR, Callanan NP, Stearns SC, DeVellis BM. Psychosocial and educational outcomes associated with home- and clinic- based pretest education and cystic fibrosis carrier testing among a population of and cystic fibrosis carrier testing among a pop

35 Lerman C, Biesecker B, Benkendorf JL, et al. Controlled trial of pretest education approaches to enhance informed decision-making for BRCA1 gene testing. F Natl Cancer Inst 1997;89:148-57.

36 Jyrinki E. Kysely ja haastattelu tutkimuksessa. Helsinki: Gaudeamus, 1974. 